\title{
Solid Loss of Carrots During Simulated Gastric Digestion
}

\author{
Fanbin Kong $\cdot$ R. Paul Singh
}

Received: 26 February 2010 / Accepted: 13 September 2010/Published online: 25 September 2010

(C) The Author(s) 2010. This article is published with open access at Springerlink.com

\begin{abstract}
The knowledge of solid loss kinetics of foods during digestion is crucial for understanding the factors that constrain the release of nutrients from the food matrix and their fate of digestion. The objective of this study was to investigate the solid loss of carrots during simulated gastric digestion as affected by $\mathrm{pH}$, temperature, viscosity of gastric fluids, mechanical force present in stomach, and cooking. Cylindrical carrot samples were tested by static soaking method and using a model stomach system. The weight retention, moisture, and loss of dry mass were determined. The results indicated that acid hydrolysis is critical for an efficient mass transfer and carrot digestion. Internal resistance rather than external resistance is dominant in the transfer of soluble solids from carrot to gastric fluid. Increase in viscosity of gastric fluid by adding $0.5 \%$ gum $(w / w)$ significantly increased the external resistance and decreased mass transfer rate of carrots in static soaking. When mechanical force was not present, $61 \%$ of the solids in the raw carrot samples were released into gastric fluid after $4 \mathrm{~h}$ of static soaking in simulated gastric juice. Mechanical force significantly increased solid loss by causing surface erosion. Boiling increased the disintegration of carrot during digestion that may favor the loss of solids meanwhile reducing the amount of solids available for loss in gastric juice. Weibull function was successfully
\end{abstract}

F. Kong $\cdot$ R. P. Singh $(\bowtie)$

Department of Biological and Agricultural Engineering,

University of California,

Davis, CA 95616, USA

e-mail: rpsingh@ucdavis.edu

R. P. Singh

Riddet Institute, Massey University,

Palmerston North, New Zealand used to describe the solid loss of carrot during simulated digestion. The effective diffusion coefficients of solids were calculated using the Fick's second law of diffusion for an infinite cylinder, which are between $0.75 \times 10^{-11}$ and $8.72 \times$ $10^{-11} \mathrm{~m}^{2} / \mathrm{s}$, depending on the $\mathrm{pH}$ of the gastric fluid.

Keywords Solid loss · Mass transfer - Carrots · Digestion · Disintegration · Diffusion - Weibull function - Effective diffusion coefficient

\section{Introduction}

Food bioaccessibility is the first limiting parameter that determines the bioavailability of food nutrients and has become a priority area for current food research. ${ }^{5,7,10}$ This information is important for developing structured foods for health benefits. Solid loss kinetics and mechanisms are important characteristics of a food system during digestion. In our previous studies, we have developed an in vitro stomach model that mimics gastric conditions to study the effects of gastric environment on digestion and disintegration of foods, as well as the release of solids and nutrient from the food matrix. ${ }^{11,13}$

When food enters the stomach, it is mixed with gastric juice due to peristaltic movement of the gastrointestinal (GI) tract. During digestion, food is subjected to both hydrodynamic mixing and mechanical force. Mechanical force results from continuous stomach contraction that imposes a considerable force on foods and causes their disintegration. Food disintegration is dominated by either fragmentation or erosion, depending on the physical forces acting on food and the cohesive forces present within the food matrix. ${ }^{12}$ Surface erosion is defined as the wearing away of food surface by an impinging gastric fluid 
containing other food solids that cause normal impact, friction, and shear forces acting on the food surface. It is the dominant mechanism when the applied stress is less than a critical stress. When applied stress is higher than the critical stress, fragmentation could occur, in which food is disintegrated into several relatively large pieces of particulates. ${ }^{12}$ Two factors appear to dominate solid loss from a food particulate in gastric environment: mass transfer of soluble solids from food to gastric fluid due to diffusion and the erosion of food surface due to mechanical force. Two countercurrent mass transfer processes occur where diffusion phenomena play significant roles:

1. Diffusion of liquid from gastric fluid to the food. Gastric juice diffuses into the food due to the water concentration gradient providing the driving force.

2. Diffusion of solutes from food to the gastric environment, resulting in the removal of a substantial amount of solids.

In the second type of mass transfer, soluble solids (including proteins, fibers, oils, vitamins and minerals, etc.) move across the cell membranes and diffuse to the gastric fluid. The acid and enzyme in the gastric juice enhance the leaching of solids by acid hydrolysis and enzymatic reactions that reduce the forces bonding the solids within the food matrix. The concentration difference of solids is the driving force for the mass transfer of leached solids. The mass transfer can be affected by many variables, such as temperature, $\mathrm{pH}$ of the GI contents, time, viscosity, and the agitation caused by the contraction of the GI tract that causes a mixing of the GI contents. These variables could also affect the role of surface erosion on solid loss. Our previous research showed that both $\mathrm{pH}$ and temperature significantly affect carrot disintegration. ${ }^{12}$

Experimental determination of effective diffusivities can provide a convenient means of investigating the mass transfer of solute species through a variety of food materials during digestion. However, it is surprising that little attention has been given to the measurement of effective diffusivities of solutes during gastric digestion, although this information is critical in understanding the food digestion and nutrient release kinetics.

In our previous paper, ${ }^{11}$ we reported on the disintegration kinetics of carrots (Daucus carota L.) in simulated gastric environment. In this study, we will examine the loss of solids from carrots under different conditions relevant to gastric digestion. Carrot is a good source of $\beta$-carotene, thiamine, iron, vitamin $C$, and sugar. It is usually consumed in the raw and cooked forms. The objectives of this study were to (1) investigate the solid loss kinetics in carrots during simulated gastric digestion and the influence of $\mathrm{pH}$, temperature, viscosity of gastric fluids, mechanical force, and cooking; and (2) use Weibull function to describe the solid loss from carrots and Fick's second law to determine the diffusion coefficients.

\section{Material and Methods}

\section{Materials and Sampling}

Baby carrots (Grimmway Farms, Bakersfield, CA) were purchased from a local grocery store. Care was taken to select carrots with similar length $(4.5-5.5 \mathrm{~cm})$ and weight (8-9.5 g). Cylindrical samples were cut from carrot core (parallel to the carrot length) using a core cutter. Sample size was selected to be $6 \mathrm{~mm}$ in diameter and length, which is close to the upper limit of the actual size range of carrot particulates after chewing ${ }^{11}$ to facilitate convenient sample loading and to achieve a substantial mass loss in the experiment. Cooked carrots were prepared by boiling the samples in water $\left(100{ }^{\circ} \mathrm{C}\right)$ for $2 \mathrm{~min}$ and cooled at room temperature before use.

Simulated gastric juice and saliva were prepared as described in our previous paper. ${ }^{11}$ Simulated gastric juice (pH 1.8) comprised of pepsin $(1 \mathrm{~g} / \mathrm{L})$, gastric mucin $(1.5 \mathrm{~g} / \mathrm{L})$, and $\mathrm{NaCl}(8.775 \mathrm{~g} / \mathrm{L})$. Simulated saliva contained gastric mucin $(1 \mathrm{~g} / \mathrm{L}), \alpha$-amylase $(2 \mathrm{~g} / \mathrm{L}), \mathrm{NaCl}(0.117 \mathrm{~g} / \mathrm{L}), \mathrm{KCl}$ $(0.149 \mathrm{~g} / \mathrm{L})$, and $\mathrm{NaHCO}_{3}(2.1 \mathrm{~g} / \mathrm{L})$. All chemicals were purchased from Sigma-Aldrich, Inc. (USA).

\section{Static Soaking Test}

The samples were first soaked in the simulated saliva at $37{ }^{\circ} \mathrm{C}$ for $15 \mathrm{~s}$ to incorporate the effect of oral exposure on food digestion and blotted to remove excess water. The weights were measured using a balance as initial weight, $W_{0}(\mathrm{~g})$. Then, the samples were soaked in gastric juice in a $37{ }^{\circ} \mathrm{C}$ water bath for $10,20,30,40,50,60,120$, and $240 \mathrm{~min}$. Each sample was suspended in $20 \mathrm{~mL}$ gastric juice in a test tube using a rigid steel wire. After soaking time, $t$, the weights of samples, $W_{t}(\mathrm{~g})$, were measured again. The moisture of samples was determined using a hot air oven at $105{ }^{\circ} \mathrm{C}$ to reach a constant weight. $M_{0}(\%)$ and $M_{t}(\%)$ were denoted as initial moisture and the moisture after soaking time $t$ (wet basis), respectively. Dry solid mass of samples was calculated based on the sample weight and moisture. Weight retention ratio (WR), dry solid retention ratio (SR), and dry solid loss ratio (SL) were calculated as follows:

$\mathrm{WR}_{t}=\frac{W_{t}}{W_{0}}$ 
where $W_{0}(\mathrm{~g})$ is initial weight and $W_{t}(\mathrm{~g})$ is the sample weight after time $t(\mathrm{~min})$.

$\mathrm{SR}_{t}=\frac{S_{t}}{S_{0}}$

$\mathrm{SL}_{t}=1-\mathrm{SR}_{t}$

where $S_{0}$ is initial dry solids (g) and $S_{t}(\mathrm{~g})$ is the dry solids after trial time $t$ ( $\mathrm{min})$.

Samples were also soaked for $36 \mathrm{~h}$, and the weight change, moisture, and mass loss were determined. The calculated dry solid retention and loss ratio were regarded as the equilibrium solid retention $\left(\mathrm{SR}_{\infty}\right)$ and loss $\left(\mathrm{SL}_{\infty}\right)$.

In Vitro Digestion of Carrots in the Model Stomach System

The in vitro digestion test of carrots was conducted in a model stomach system as described in our previous papers. ${ }^{11-13}$ The model stomach system has the advantage of providing constant mechanical force during the trial and convenient measurement of sample weight, which makes it suitable for investigating the solid loss and mass transfer phenomenon of individual food particulates.

The samples were tested under two different experimental settings, depending on whether or not plastic beads were added into the simulated gastric juice. These plastic beads have a size of 3-mm diameter and specific gravity of 1.03 and were incorporated into gastric juice to mimic food particulates in human stomach. When plastic beads were not combined into the gastric juice, which is referred to as "trial A," samples were only subjected to hydrodynamic shearing stress caused by the rotating fluid; when plastic beads were combined into the gastric juice, referred to as "trial B," a mechanical force was created resulting from the beads impacting and grinding the samples that caused erosion of food surface, simulating the effect of contraction forces present in human stomach due to peristaltic movement. Using beads to create mechanical force in the in vitro stomach system was first proposed by Aoki et al. ${ }^{1}$ to study drug dissolution. This approach has been effectively used in our model stomach system to create mechanical force simulating the force received by foods in human stomach. ${ }^{11}$ It is assumed that the mass transfer was the only mechanism responsible for solid loss from carrot in trial A, while in trial $\mathrm{B}$, both mass transfer and surface erosion contributed to carrot solid loss.

The procedures of trials $\mathrm{A}$ and $\mathrm{B}$ were described in a previous paper. ${ }^{13}$ For trial A, samples were first soaked in the simulated saliva for $15 \mathrm{~s}\left(37^{\circ} \mathrm{C}\right)$. The sample surface moisture was blotted using a filter paper, and the weight of the sample was determined as the initial weight, $W_{0}(\mathrm{~g})$. The samples were then tested in the model stomach system. The model contained $500 \mathrm{~mL}$ of simulated gastric juice, with a rotation speed set at $30 \mathrm{rpm}$. For each trial, four samples were tested simultaneously. The force measured using a load cell was approximately $0.001 \mathrm{~N}$ for each sample. The trials were continued until 10, 20, 30, 40, 50, 60,120 , and $240 \mathrm{~min}$, respectively. The maximum digestion time of $4 \mathrm{~h}$ was selected to cover residence time for gastric exposure as most solids are emptied within 4$5 \mathrm{~h}$. Upon the completion of the trial, the model was stopped and samples were taken out, and the excess surface moisture was removed with a filter paper. The weight of samples was measured as $W_{t}(\mathrm{~g})$. The moisture and dry mass content were subsequently determined for each sample.

For trial B, 330-g plastic beads were combined with $170 \mathrm{~mL}$ simulated gastric juice to make $500 \mathrm{~mL}$ simulated gastric content. The trials were conducted following the same procedure as in trial A. The mechanical force generated by beads impacting on a sample was approximately $0.2-0.25 \mathrm{~N}$, which is within the range of maximum mechanical force present in the human stomach. ${ }^{12}$ The trials were continued until the sample weight loss reached $60 \%$. The weight retention, moisture, and dry solid retention ratio of samples for each trial were determined accordingly.

\section{Role of Gastric Environment on Solid Loss Kinetics}

\section{pH and Temperature}

Ingestion of foods may significantly change the intragastric temperature and $\mathrm{pH}^{3,20}$ To investigate the influence of temperature and $\mathrm{pH}$ as well as other components of gastric juice such as salt and mucin on carrot digestion, samples were tested by static soaking in different media, including deionized (DI) water $(\mathrm{pH}$ 5.3) at room temperature $\left(23 \pm 1{ }^{\circ} \mathrm{C}\right)$ and body temperature $37{ }^{\circ} \mathrm{C}$, and acidic water $(\mathrm{pH} 1.8$, prepared by adding $1 \mathrm{~N} \mathrm{HCl}$ into DI water) at room and body temperatures. The change of weight, moisture, and dry mass of the samples were compared with the trials using the simulated gastric juice.

\section{Viscosity of Gastric Contents}

The viscosity of gastric fluid can vary dramatically with ingestion of foods and liquids. ${ }^{2,14}$ To study how viscosity of gastric fluids affects digestion, gum was added to gastric juice to obtain a concentration of $0.5 \%(w / w)$. Samples were tested with static soaking and the model stomach system, respectively. 


\section{Influence of Cooking}

Food processing can significantly affect the disintegration rate of carrots. ${ }^{10}$ To study how cooking influences the solid loss of carrots, carrots were cooked for $2 \mathrm{~min}$ in boiling water. The weights of carrots before and after cooking were measured. The moisture and the dry mass of cooked carrots were determined. The amount of solids lost in the cooking water was calculated as the difference of the dry mass present in the carrots before and after cooking. The cooked carrots were tested using the static soaking test and the model system as described previously.

Determination of Effective Diffusion Coefficients of Solids in Carrots as Affected by $\mathrm{pH}$

Cylinders of carrot tissue were cut longitudinally using a cork borer to obtain cylinders of core tissue $0.03 \mathrm{~m}$ in length and $0.0035 \mathrm{~m}$ in diameter. A thin steel wire was passed diametrically through the center of each carrot cylinder. Twenty-four samples were immersed in $4 \mathrm{~L}$ simulated gastric juice in a shaking water bath to obtain an infinite volume. Every two carrot cylinders were about $0.08 \mathrm{~m}$ apart. The gastric juice was maintained at $37{ }^{\circ} \mathrm{C}$. The water bath was shaken at a low speed to allow a gentle agitation of the liquid, thereby minimizing any external resistances to mass transfer. At each time interval corresponding to $10,20,40,60,90,120,180$, and $240 \mathrm{~min}$ after immersion, respectively, three samples were removed from the water bath. These samples were slightly blotted, and the weight and dry solids were determined as previously described. The trials were conducted at three $\mathrm{pH}$ levels of gastric juice: 1.8, 3.5, and 5.3, respectively.

Fick's second law was used to determine the diffusion coefficient of solids in the carrots during digestion. The solution of Fick's second law for an infinite cylinder can be expressed as follows: $:^{4,18}$

$\frac{S_{t}}{S_{0}}=\sum_{n=1}^{\infty} \frac{4}{\beta_{n}^{2}} \exp \left(\frac{-\beta_{n}^{2} D_{e} t}{R^{2}}\right)$

where $D_{\mathrm{e}}$ is the effective diffusion coefficient (radial direction, $\left.\mathrm{m}^{2} \mathrm{~s}^{-1}\right), R$ is the initial sample radius (m), and $t$ is time (s). $\beta_{\mathrm{n}}$ is the Bessel function roots $\left(\beta_{1}=2.4048\right)$. Using only one term of the series, a plot of $\ln \left(S_{t} / S_{0}\right)$ vs. t yields a straight line with gradient $\left(\beta_{n}{ }^{2} D_{\mathrm{e}} / R^{2}\right)$ from which the value of $D_{\mathrm{e}}$ may be calculated.

\section{Statistical Analysis}

The Solver command in EXCEL software was used to obtain model parameters. The root mean square error (RMSE), the correlation coefficient $(r)$, and the coefficient of determination $\left(R^{2}\right)$ were used as the criteria for evaluating the performance of the models. A significance test was conducted using analysis of variance in the general linear model procedure of the SAS System. Differences between group means were analyzed by Duncan's multiplerange test. Statistical significance was set at a probability level of 0.05. All the tests were conducted with three replicates.

\section{Results and Discussion}

Role of Acid and Temperature on Carrot Digestion

Upon ingestion of food, stomach secretes gastric juice, but it may take considerable time (up to $2 \mathrm{~h}$ ) to recover to its original $\mathrm{pH}(1.5-2.5){ }^{3}$ Meal temperature can also affect intragastric temperature and, subsequently, the rate of gastric emptying. After ingestion of $400 \mathrm{~mL}$ cold orange juice $\left(4{ }^{\circ} \mathrm{C}\right)$, intragastric temperature can decrease to $21.2{ }^{\circ} \mathrm{C}$ within $45 \mathrm{~s}$ and return to body temperature after half an hour. ${ }^{20}$ The effect of the variation of intragastric temperature and $\mathrm{pH}$ on solid loss of food remains to be elucidated.

Figure 1 shows the effect of temperature and $\mathrm{pH}$ on carrot digestion where carrots were soaked in acidic and non-acidic water up to $4 \mathrm{~h}$. Here, the terms "acidic" and "non-acidic" are used to indicate the water with acid adjustment to $\mathrm{pH} 1.8$ and without acid addition. The rate of weight change, moisture increase, and solid loss all occurred faster in the beginning then gradually decreased. There is a slight increase in the weight of carrots soaked in non-acidic water $(\mathrm{WR}>1)$ at both 23 and $37{ }^{\circ} \mathrm{C}$, while in acidic water, there was a significant decrease in total weight at both temperatures $(\mathrm{WR}<1)$ (Figure 1a). When comparing the solid loss (Figure 1c), a significant solid loss occurred in the carrots soaked in acidic water at both temperatures. The highest amount of solid loss occurred in acidic water and $37{ }^{\circ} \mathrm{C}$; about $61 \%$ of the solids were lost $(\mathrm{SR}=0.39)$. Carrots soaked in acidic water at 23 and $37{ }^{\circ} \mathrm{C}$ for $4 \mathrm{~h}$ had a similar amount of solid loss, although initially, the rate of solid loss in the carrots soaked at $23{ }^{\circ} \mathrm{C}$ was slower than that at $37{ }^{\circ} \mathrm{C}$ (Figure 1c). A small solid loss $(\mathrm{SR}=0.87$ at $4 \mathrm{~h}$ ) occurred for carrots soaked in $37{ }^{\circ} \mathrm{C}$ non-acidic water, and the least solid loss occurred in carrots soaked in nonacidic water at $23{ }^{\circ} \mathrm{C}(\mathrm{SR}=0.94)$. The moisture changes in the soaked carrots show a good correlation with solid loss; a higher moisture increase occurred in samples soaked in the acidic water, and the carrot moisture increased from initially $89 \%$ to $95 \%$ after $4 \mathrm{~h}$ of soaking. Carrots soaked in non-acidic water had small water absorption, and the moisture increased from $89 \%$ to $90.3 \%$ and $91.3 \%$, respectively, at 23 and $37{ }^{\circ} \mathrm{C}$. From these results, it is 

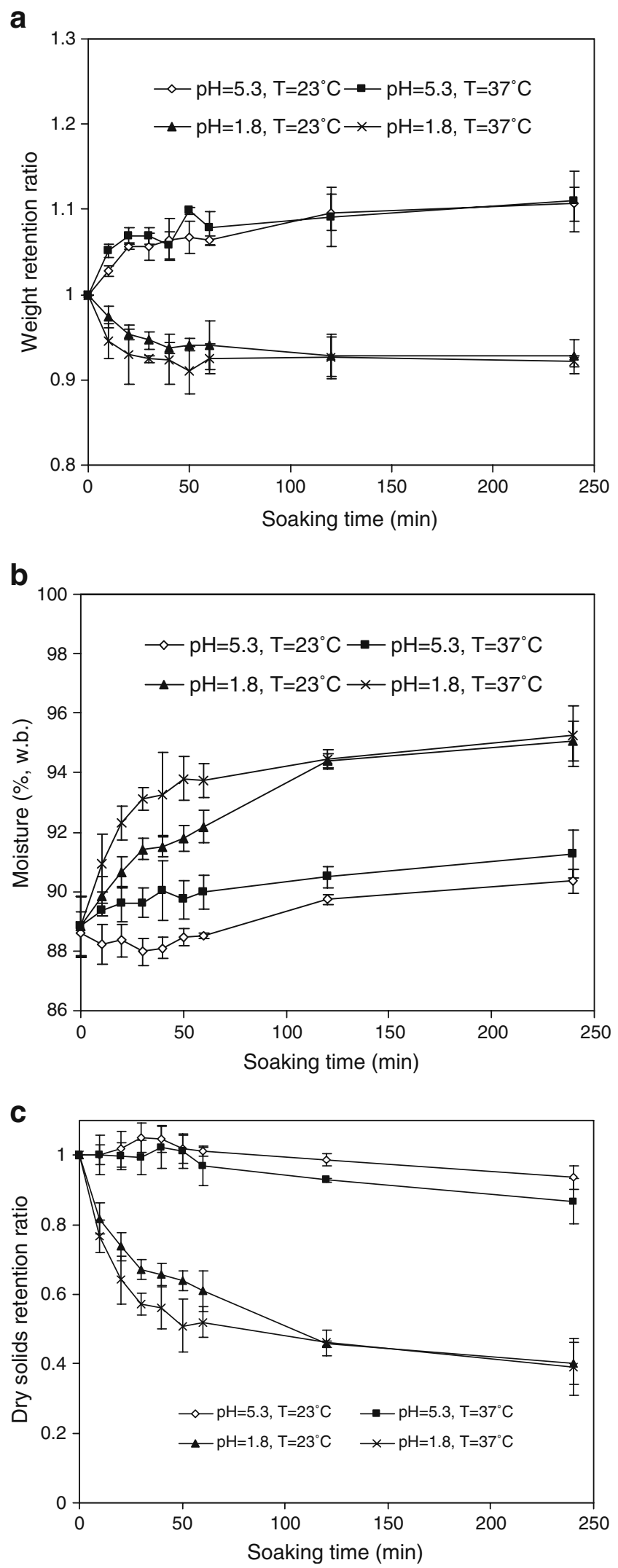

Fig. 1 Effect of water temperature and $\mathrm{pH}$ on soaked carrots: a weight retention ratio; $\mathbf{b}$ moisture; and $\mathbf{c}$ dry solids retention ratio concluded that the combination of acidic water and $37^{\circ} \mathrm{C}$ is the most efficient condition for mass transfer between carrot and soaking medium, while acidic condition is more critical than the temperature in enhancing the mass transfer. This result confirms that $\mathrm{pH}$ and temperature have a synergistic effect in food digestion, and this effect was related to the strong effect of acid and temperature in softening carrot texture. ${ }^{12}$

Carrot has approx. $1.4 \%$ pectins, in the form of protopectin, the major constituent of the middle lamella, cementing cell walls that give firmness and elasticity to tissues. When carrots are soaked in non-acidic water, the leached solutes from carrots consist typically of sucrose, reducing sugars and vitamins, minerals, and soluble protein. This process is very slow due to the high resistance of carrot tissues as the cell membranes remain intact, and the loss of nutrients occurs mainly due to osmosis. ${ }^{16}$ Under acidic environment, the protopectin is hydrolyzed to pectin due to the loss of some of its branching and chain length, and it goes into solution. The rate constant for the hydrolysis of protopectin is a function of temperature. ${ }^{15}$ Acid hydrolysis of the pectin material and its loss into the solution is believed to be the major reaction that increases the solid loss. It is reported that treatment of carrot tissues with dilute $\mathrm{HCl}(\mathrm{pH} 2.0)$ at $35{ }^{\circ} \mathrm{C}$ could extract $40 \%$ of pectic substances. ${ }^{6}$ The dissolved pectin, sucrose, reducing sugars, and other nutrients are the major components of soluble solids that transfer to the surrounding fluid.

Digestion of Carrots in Static Soaking, Trial A and Trial B

Figure 2 shows the changes in sample weight, moisture, and dry mass of raw carrots with digestion time during static soaking and trials A and B. Simulated gastric juice was used in these trials. Whereas the total weight and dry mass significantly reduced in the trial B where mechanical force was involved, generally there was no significant difference between the static soaking and trial A where no mechanical forces were present, indicating that the hydrodynamic flow on the solid loss caused by rotating fluid at $30 \mathrm{rpm}$ was not significant. When we increased rotation speed to $60 \mathrm{rpm}$, we still did not observe any significant difference in the changes of total weight, moisture, and the dry mass. Rotational speed of $60 \mathrm{rpm}$ of the fluid vessel corresponds to a flow speed of $408 \mathrm{~mm} \mathrm{~s}^{-1}$ of the gastric liquid impacting the samples, much higher than the flow velocities of gastric fluid which is approx. $7.5 \mathrm{~mm} \mathrm{~s}^{-1}$ at maximum, occurring in the antrum of stomach. ${ }^{17}$ This result implies that the hydrodynamic flow had no significant influence on solid loss and mass transfer in carrot, indicating that the mass transfer between carrot and surrounding gastric fluid is governed predominantly by the internal resistance rather than external resistance. 

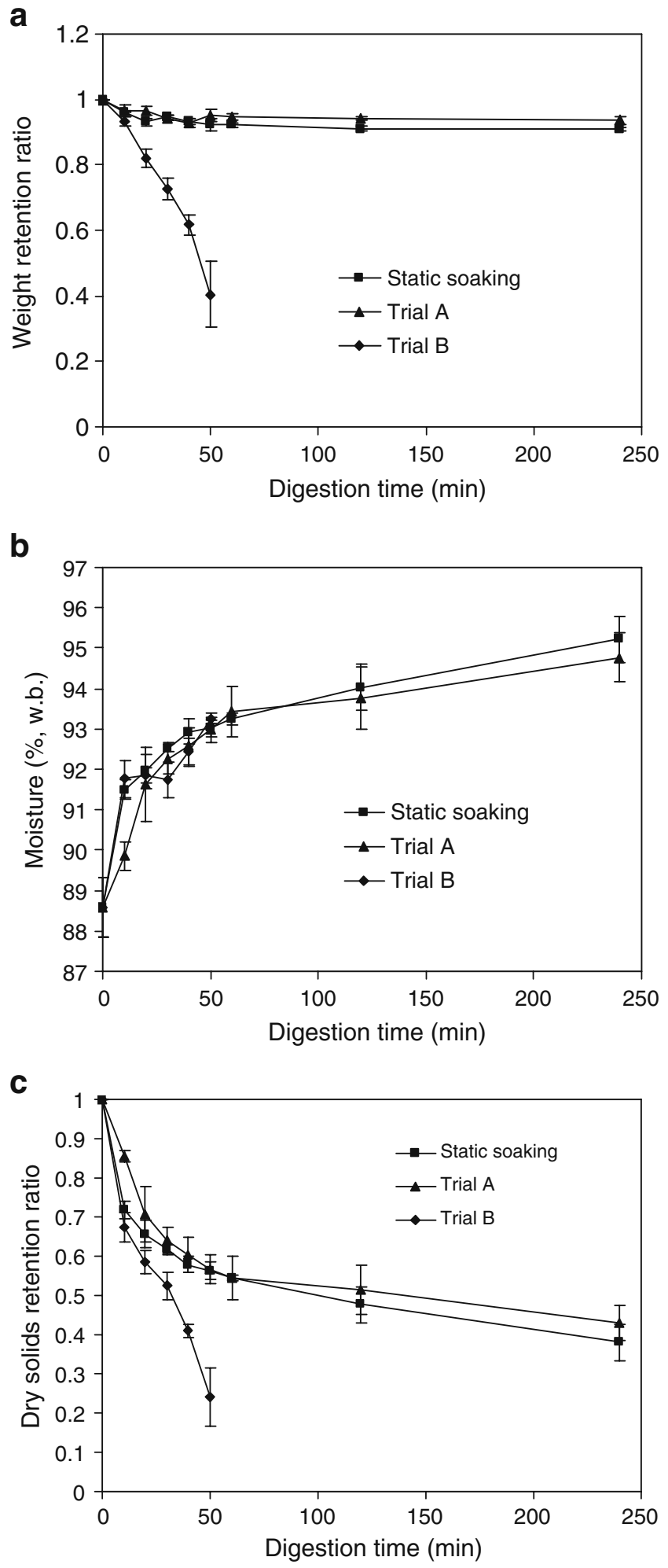

Fig. 2 In vitro digestion of carrot comparing static soaking and trial A and trial B tests: a weight retention ratio, $\mathbf{b}$ moisture, and $\mathbf{c}$ dry solids retention ratio

When comparing Figures 1 and 2, we can see that results of the mass transfer of raw carrots during static soaking in simulated gastric juice (Figure 2) are the same as that in acidic water at $37{ }^{\circ} \mathrm{C}$ (Figure 1), with a SR about 0.4 after $4 \mathrm{~h}$ of soaking. The similarity between these two conditions again proved that acid and temperature are the major factors affecting solid loss from carrot during digestion, while enzyme (pepsin), mucin, and salt contained in the simulated gastric juice have no significant influence. The insignificant effect of pepsin is expected as carrot only contains a minor amount of proteins. ${ }^{12}$

It is postulated that the diffusion of solids from food to gastric fluids during digestion involves three steps. The first is gastric medium ingression into the food matrix; the second step is the dissolution of solids in the food matrix, which involves enzymatic and acid hydrolysis that promote leaching of the solid; and, finally, the diffusion of the soluble solids across the hydrated matrix into the gastric medium. When carrot was placed in the simulated gastric juice, gastric acid and enzyme penetrated into the carrot matrix. Acidic hydrolysis of protopectin and the individual components of the cell wall resulted in the degradation of cell wall and pectin dissolution. ${ }^{8,12}$ The release of the solubilized pectin and other solids after the acid hydrolysis may involve two consecutive stages: an internal diffusion of pectin in the pores of the solid phase until it reaches the surface of carrots, followed by external diffusion where pectin is transported through the boundary layer to the gastric fluid. Therefore, the mass transfer in carrots during digestion should include the penetration of the gastric juice into the carrot matrix, chemical reactions including the hydrolysis of protopectin, and internal diffusion of the dissolved pectin in the matrix until it reaches the surface. External resistances include the mass transfer of dissolved solids through the boundary layer to the gastric fluid, i.e., external diffusion. The reason that rates of solid release decreased with time from the carrot matrix is because initially, solids are released from the surface layer which has only a short distance to travel; later, the soluble solids diffuse out from greater depth within the matrix which has a longer distance and therefore longer time to travel.

As shown in Figure 2, when mechanical force is present (trial B), the solid loss was significantly improved and the dry mass loss reached almost $76 \%$ after a 50 -min trial $(\mathrm{SR}=$ 0.24). In trial B, solid loss was not only from diffusion but also from the erosion of the carrot surface. The surface erosion reduced the sample size, moving a large amount of tiny particulates with greater surface area into solution. The reduction in sample size also led to reduced distance for gastric juice to penetrate in the carrot matrix and for dissolved solids to travel to the surface, thus improving the efficiency of mass transfer. The solid loss kinetics is largely affected by the type of foods which are different in texture and microstructure. In a separate study on the digestion of almonds, we have shown that the solid loss was only $12 \%$ in static soaking test in $5 \mathrm{~h}$, while when mechanical force was incorporated, the solid loss increased to $\sim 40-50 \%$. ${ }^{13}$ 


\section{Role of Cooking}

Cooking of carrots in boiling water for $2 \mathrm{~min}$ increased the moisture content in the carrot samples, from $88.7 \%$ to $91.5 \%$. Heating caused a disruption of cell arrangement and cell breakage as a result of the thermal destabilization of pectin materials. Heating also softened the texture due to the thermal degradation of middle lamella pectin and other cell wall polysaccharides, and the loss of turgor pressure and occluded air. ${ }^{19}$ During boiling, leaching of the solids occurred that decreased the dry mass amount of carrot samples. Our measurements indicated that 2 min of boiling caused loss of solids in the cylindrical samples up to $33.1 \%(w / w)$.

Static soaking and trial A indicated that the cooked carrots had no significant change in weight during the $4 \mathrm{~h}$ of soaking, which is different with raw carrots in which the weight significantly decreased (Figure 2). Similar to raw carrots, cooked carrots did not show significant differences in the change of moisture and dry mass of the samples between static soaking test and trial A. After $4 \mathrm{~h}$ of soaking, cooked carrots lost $44 \%$ solids $(S R=0.56)$, lower than that for raw carrots $(\mathrm{SR}=0.40)$. The final moisture of cooked carrots after $4 \mathrm{~h}$ of soaking is $95 \%$, close to that of raw carrots. The total amount of solids released in the combined boiling and digestion processes was $62.5 \%$, similar to the solid release of raw carrots in the gastric juice $(61.0 \%$; Figure 1). However, as large amounts of solids were lost in boiling water, the amount of solids released in the gastric environment was significantly lower than raw carrots: about $61 \%$ solids of raw carrots were released in the gastric juice compared to $29.4 \%$ for cooked carrots. This result indicates that boiling may significantly reduce the amount of remaining nutrients that are available for release and absorption in human GI tract.

When mechanical force was present, the disintegration rate of cooked carrots is significantly faster than raw carrots due to the softer texture caused by heat treatment disrupting the structure of carrot. The WR and SR decreased to 0.38 and 0.30 , respectively, after a $25-\mathrm{min}$ trial. When raw carrot was tested in trial $\mathrm{B}$, a period of $50 \mathrm{~min}$ was needed to reach similar levels of WR and SR (Figure 2). This result indicated that cooking reduced the internal cohesive force in the carrot matrix, leading to a significantly faster disintegration. As described above, the fast surface erosion may improve the efficiency of mass transfer. Therefore, boiling resulted in increased disintegration that may favor nutrient release, although it reduced nutrient amount available for release.

Role of Viscosity of Gastric Environment

Addition of $0.5 \%$ gum into the gastric juice increased the viscosity from $0.01 \mathrm{~Pa} \mathrm{~s}$ at zero-shear viscosity (obtained from the viscosity/shear rate profiles, covering 30 shear rates from 0.1 to $1,0001 / \mathrm{s}$ ) to $0.07 \mathrm{~Pa} \mathrm{~s}$, which is in the range of human digesta (Marciani et al. 2000; Abrahamsson et al. 2005). Figure 3 shows the in vitro digestion results of raw carrot in the simulated gastric juice with $0.5 \%$ gum comparing static soaking, trial $\mathrm{A}$, and trial $\mathrm{B}$. When comparing Figures 2 and 3, it can be seen that the addition of $0.5 \%$ gum did not affect the results of both trial $\mathrm{A}$ and trial B of carrots in terms of weight change, solid loss, and the moisture change. However, it did affect the results of static soaking: the water absorption and solid loss of carrots decreased when gum was combined (Figures 2 and 3). This is possibly due to the high-viscosity fluid increasing the external resistance to mass transfer. This result indicates that the addition of $0.5 \%$ gum may have significantly increased external resistance so that the mass transfer in static soaking was governed by both internal and external resistances.

In trial $\mathrm{A}$ and trial $\mathrm{B}$, the movement of the fluid caused a shearing and mixing effect on carrot by impacting the fixed sample, quickly diluting the solid concentration at the solid-liquid interface, providing the renewal of the solution in contact with the carrot samples and restoring a concentration difference that favored mass transfer. Therefore, the results of carrot digestion in trial A and trial B as shown in Figure 3 are similar to that of raw carrots tested in gastric juice without gum addition (Figure 2).

\section{Determination of Effective Diffusivity Coefficients of Solids}

A previous study has shown that $\mathrm{pH}$ is critical for carrot digestion and solid loss. In vivo studies have shown that the $\mathrm{pH}$ of the gastric contents may rise to 5-7 after ingestion of a meal, and it may take up to $2 \mathrm{~h}$ to return to $\mathrm{pH}<2$. $^{3}$ Therefore, it is important to understand how the $\mathrm{pH}$ variation may cause the change in the mass transfer, especially its influence on solid loss which is directly related to the bioaccessibility of nutrients. In this study, we obtained the diffusion coefficients of solids in carrots during digestion in simulated gastric juice at three different $\mathrm{pH}$ levels: $1.8,3.5$, and 5.3. A typical plot of $\ln \left(S_{t} / S_{0}\right)$ vs. $t$ for solid loss of carrot cylinders is shown in Figure 4 . The graphs were found to consist of two straight lines, which suggest that two effective diffusion coefficients or two stages characterize the diffusion process of solids. $D_{\mathrm{e} 1}$ represents the initial period of diffusion, which has a high rate of solid loss, and $D_{\mathrm{e} 2}$ the final stage of diffusion, where solid release rates decline. Table 1 shows $D_{\mathrm{e} 1}$ and $D_{\mathrm{e} 2}$ values for solid loss of carrot cylinders at different $\mathrm{pH}$ values. The $D_{\mathrm{e}}$ values ranged from $0.75 \times 10^{-11}$ to $8.72 \times$ $10^{-11} \mathrm{~m}^{2} / \mathrm{s}$. Both $D_{\mathrm{e} 1}$ and $D_{\mathrm{e} 2}$ values decreased with an increase in $\mathrm{pH}$ value, emphasizing the influence of acid in 


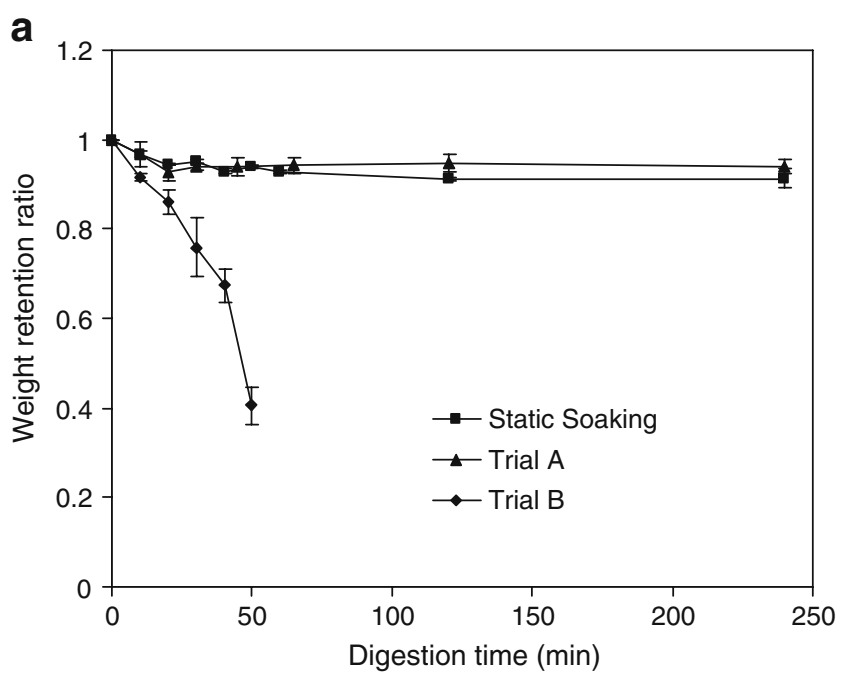

b

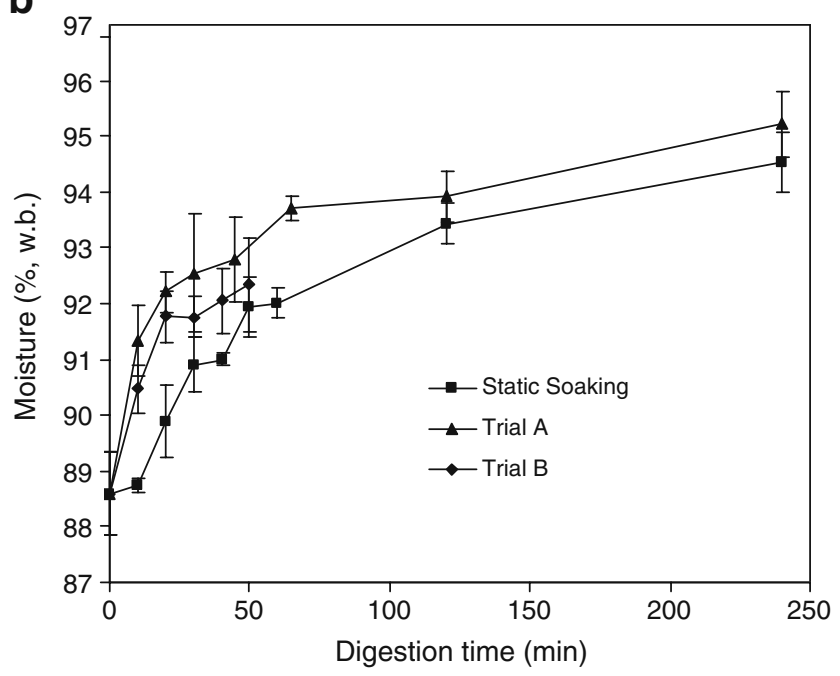

C

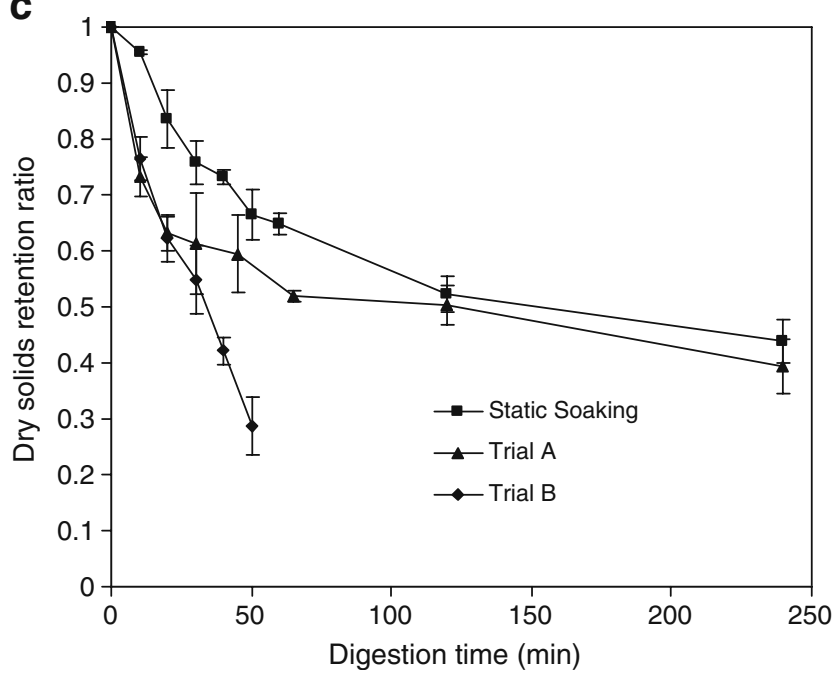

Fig. 3 In vitro digestion of raw carrot in simulated gastric juice with $0.5 \%$ gum addition comparing static soaking, trial $\mathrm{A}$, and trial $\mathrm{B}$ : a weight retention ratio, $\mathbf{b}$ moisture, and $\mathbf{c}$ dry solids retention ratio

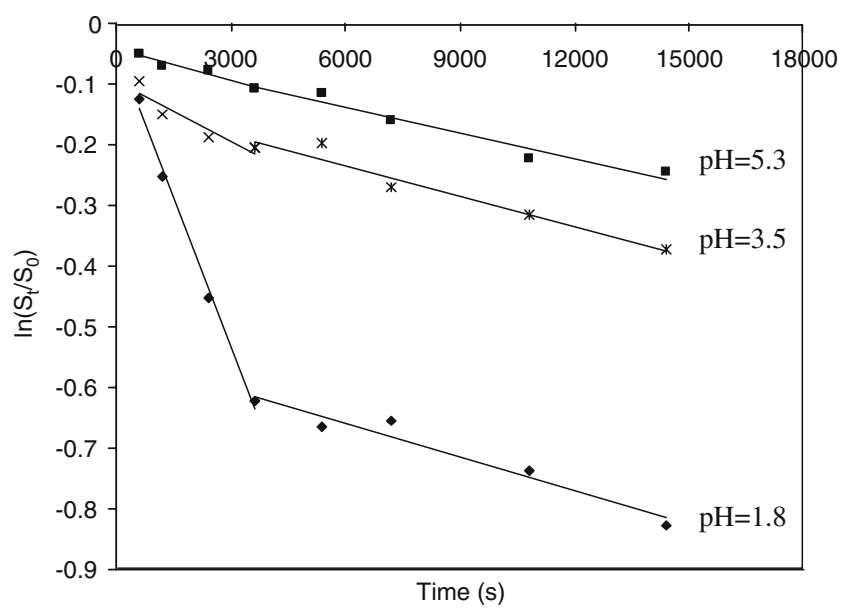

Fig. 4 Graphical determination of $D_{\mathrm{e}}$ for solids in carrots during digestion

the digestion process. For a given $\mathrm{pH}$ value, $D_{\mathrm{e} 1}$ was greater than $D_{\mathrm{e} 2}$, confirming that diffusion was more rapid in the initial stages of digestion. As mentioned previously, this initial period of high solid loss may be attributed to the fact that initially solids are released from the surface layer which has only a short distance to travel. In addition, capillaries and cavities near the surface may facilitate a faster acid penetration and hydrolysis, causing a rapid leaching of the solids. It is also noted that $D_{\mathrm{e} 1}$ values are significantly different among the three $\mathrm{pH}$ values, while $D_{\mathrm{e} 2}$ values are close. No previous study on the mass transfer coefficients of food during gastric digestion was found in the literature. However, the $D_{\mathrm{e}}$ values for total solute loss of carrots during blanching for times up to $1,800 \mathrm{~s}$ were determined and found to be in the range $3 \times 10^{-10}-8 \times$ $10^{-10} \mathrm{~m}^{2} / \mathrm{s} .{ }^{18}$ The higher $D_{\mathrm{e}}$ values are believed to result from the higher temperature employed $\left(60-90{ }^{\circ} \mathrm{C}\right)$. The temperature dependence of $D_{\mathrm{e}}$ was found to follow the Arrhenius type equation. ${ }^{18}$

Modeling the Solid Loss of Carrots Under Different Conditions

Weibull function was used to describe the solid loss of foods during static soaking and trials $\mathrm{A}$ and $\mathrm{B}$ :

$R_{S L}=1-\exp \left(-a t^{b}\right)$

where $R_{\mathrm{SL}}$ is the ratio of solid loss, i.e.,

$R_{S L}=\frac{\mathrm{SL}_{t}}{\mathrm{SL}_{\infty}}=\frac{1-\mathrm{SR}_{t}}{1-\mathrm{SR}_{\infty}}=\frac{S_{0}-S_{t}}{S_{0}-S_{\infty}}$

where $\mathrm{SL}_{t}$ and $\mathrm{SL}_{\infty}$ represent the solid loss at time $t$ and infinite time, i.e., the maximum amount of solid loss or equilibrium solid loss. Constant $a$ is a scale parameter that defines the timescale of the process. Constant $b$ is a 
Table $1 D_{\mathrm{e}}$ values of solid loss in carrots during simulated gastric digestion

\begin{tabular}{ccccc}
\hline $\mathrm{pH}$ & $D_{\mathrm{e} 1}\left(\times 10^{-11} \mathrm{~m}^{2} / \mathrm{s}\right)$ & $R^{2}$ & $D_{\mathrm{e} 2}\left(\times 10^{-11} \mathrm{~m}^{2} / \mathrm{s}\right)$ & $R^{2}$ \\
\hline 1.8 & 8.72 & 0.995 & 0.97 & 0.952 \\
3.5 & 1.80 & 0.875 & 0.88 & 0.950 \\
5.3 & 0.94 & 0.937 & 0.75 & 0.959 \\
\hline
\end{tabular}

shape parameter characterizing the curve as either exponential $(b=1)$, sigmoidal $(b>1)$, or parabolic $(b<1)$. The maximum solid loss was determined by soaking carrot samples for $36 \mathrm{~h}$. After $36 \mathrm{~h}$ of soaking, the $\mathrm{SR}_{\infty}$ were $0.37 \pm 0.03,0.54 \pm 0.04$, and $0.39 \pm 0.04$ for raw carrots, cooked carrots soaked in gastric juice without addition of gum, and raw carrots soaked in simulated gastric juice with $0.5 \%$ gum, respectively. When Eq. 5 is used to describe the solid loss for trial $\mathrm{B}, S_{\infty}=0$ as all of the solids will be lost eventually. Weibull function has been used to describe the dissolution kinetics of drugs as well as the release kinetics. ${ }^{9}$

The half-time $t_{1 / 2}$, the time to reach $50 \%$ loss of total solid loss, is calculated as the following:

$t_{1 / 2}=\left(-\frac{\ln 0.5}{a}\right)^{\frac{1}{b}}$

Equation 5 was fitted with the data of trials. The equilibrium solid loss ratio $\mathrm{SL}_{\infty}$, equation parameters $a$ and $b, t_{1 / 2}$, RMSE and $r$ values for static soaking and trial B were summarized in Table 2. These values for trial A are not presented as they are generally similar to static soaking. All the $b$ values are $<1$, indicating a higher initial rate of solid release followed by an exponential decrease in the loss of solids with soaking time. The low RMSE and $r$ close to 1 indicate a good fit of the equation with the data for all the cases. It shows that when the mechanical force is present, cooked carrot has the highest solid loss rate in trial $\mathrm{B}$ due to its fastest disintegration. Although this equation has a good fit to the trial data, it should be noted that it may not necessarily relate to any underlying mechanism.
In our previous studies, we have used a modified power exponential function ${ }^{11}$ and a linear-exponential equation ${ }^{12}$ to describe the change of the total weight of foods during digestion. However, the change of total weight of foods during gastric digestion results not only from the solid loss, but also from the gain in water. For example, this study showed that while no significant change occurred in the total weight of cooked carrot after the 4-h soaking test in gastric juice, its solid loss had reached $44 \%$. Together, the mathematical models for weight retention and the Weibull function we proposed here for solid loss provide a more comprehensive description of the digestion of solid foods.

\section{Conclusion}

1. Solid loss of carrot particulates during digestion is a result of diffusion of soluble solids and surface erosion. The mass transfer in carrots involves acid penetration into food matrix, hydrolysis of pectin materials, and their transfer into the gastric medium.

2. Mass transfer of the solids from carrot to gastric medium is governed predominantly by the internal resistance rather than external resistance. The external resistance was significantly increased when $0.5 \%(w / w)$ gum is added to increase the viscosity of simulated gastric environment.

3. When mechanical force is not present, a maximum of $61 \%$ of the solids in the raw carrot samples could be released into gastric media in $4 \mathrm{~h}$ by diffusion, while mechanical force significantly increased solid loss by causing surface erosion.

4. Boiling resulted in increased disintegration of carrot during digestion that may favor the release of solids and reduced the amount of solids available to release.

5. $D_{\mathrm{e}}$ values of solid loss in carrots during gastric digestion ranged between $0.75 \times 10^{-11}$ and $8.72 \times$ $10^{-11} \mathrm{~m}^{2} / \mathrm{s}$, depending on the $\mathrm{pH}$ of gastric fluid.

Table 2 Parameter values of Weibull function (Eq. 5) fitted to the solid loss data of carrots at different conditions

\begin{tabular}{lllccccc}
\hline & $\mathrm{SL}_{\infty}$ & $a\left(\times 10^{-2}\right)$ & $b$ & $\mathrm{RMSE}\left(\times 10^{-2}\right)$ & $r$ & $t_{1 / 2}{ }^{\mathrm{a}}(\mathrm{min})$ \\
\hline Static soaking & Raw carrot & 0.63 & 17.77 & 0.494 & 2.20 & 0.9970 \\
& Cooked carrot & 0.46 & 10.57 & 0.589 & 3.30 & 0.9920 & 24.39 \\
& Raw carrot + 0.5\%gum & 0.61 & 1.99 & 0.918 & 3.28 & 0.9937 & 47.90 \\
\multirow{2}{*}{ Trial B } & 1 & 5.30 & 0.788 & 4.70 & 0.9800 & 26.14 \\
& Raw carrot & 1 & 5.72 & 0.927 & 1.93 & 0.9965 & 14.75 \\
& Cooked carrot & 1 & 2.63 & 0.959 & 2.73 & 0.9930 \\
\hline
\end{tabular}

${ }^{\mathrm{a}} t_{1 / 2}$ (half-time), the time to reach $50 \%$ of $\mathrm{SL}_{\infty}$ (equilibrium solid loss ratio) 
6. Weibull function describes well the solid loss of carrot during simulated digestion.

Acknowledgment This project was supported by the USDA-NRIContract 2009-35,503-05,195.

Open Access This article is distributed under the terms of the Creative Commons Attribution Noncommercial License which permits any noncommercial use, distribution, and reproduction in any medium, provided the original author(s) and source are credited.

\section{References}

1. S. Aoki, K. Uesugi, K. Tatsuishi, H. Ozawa, M. Kayano, Evaluation of the correlation between in vivo and in vitro release of phenylpropanolamine $\mathrm{HCl}$ from controlled-release tablets. Int $\mathrm{J}$ PharmMed 85, 65-73 (1992)

2. B. Abrahamsson, A. Pal, M. Sjoberg, M. Carlsson, E. Laurell, J.G. Brasseur, A novel in vitro and numerical analysis of shearinduced drug release from extended release tablets in the fed stomach. PharmRes 22(8), 1215-1226 (2005)

3. W.N. Charman, C.J. Porter, S. Mithani, J.B. Dressman, Physiochemical and physiological mechanisms for the effects of food on drug absorption: the role of lipids and $\mathrm{pH}$. Journal of Pharmaceutical Sciences 86(3), 269-282 (2000)

4. J. Crank, The mathematics of diffusion, 2nd edn. (Oxford University Press, London, 1975)

5. G.S.M.J.E. Duchateau, W. Klaffke, Product composition, structure, and bioavailability. Food Biophysics 3, 207-212 (2008)

6. M. Fuchigami, K. Okamoto, Fractionation of pectic substances in several vegetables by successive extraction with dilute hydrochloric acid and acetate buffer solutions. Nippon Eiyo Shokuryo Gakkaishi [J Jap Soc Nutri Food Sci] 37, 57-64 (1984)

7. B. Holst, G. Williamson, A critical review of the bioavailability of glucosinolates and related compounds. Nat Prod Rep 21, 425-447 (2004)
8. D.K. Khalikov, M.G. Mukhiddinov, M.G. Asoev, V.A. Degtyarev, Some kinetic features of the hydrolysis of protopectin. Chemistry of Natural Compounds 30(6), 734-738 (1994)

9. K. Kosmidis, P. Argyrakis, P. Macheras, A reappraisal of drug release laws using Monte Carlo simulations: the prevalence of the Weibull function. Pharm Res 20, 988-995 (2003)

10. F. Kong, R.P. Singh, Disintegration of solid foods in human stomach. J Food Sci 73(5), R67-R80 (2008)

11. F. Kong, R.P. Singh, A model stomach system to investigate disintegration kinetics of solid foods during gastric digestion. J Food Sci 73(5), E202-E210 (2008)

12. F. Kong, R.P. Singh, Modes of disintegration of solid foods in simulated gastric environment. Food Biophysics 4(3), 180-190 (2009)

13. F. Kong, R.P. Singh, Digestion of raw and roasted almonds in simulated gastric environment. Food Biophysics 4(4), 365-377 (2009)

14. L. Marciani, P.A. Gowland, R.C. Spiller, P. Manoj, R.J. Moore, P. Young, S. Al-Sahab, D. Bush, J. Wright, A.J. Fillery-Travis, Gastric response to increased meal viscosity assessed by echo-planar magnetic resonance imaging in humans. J Nutr 130, 122-127 (2000)

15. S. Minkov, A. Minchev, K. Paev, Modelling of the hydrolysis and extraction of apple pectin. Journal of Food Engineering 29, 107-113 (1996)

16. F.A.R. Oliveira, C.L.M. Silva, Freezing influences diffusion of reducing sugars in carrot cortex. Journal of Food Science 57(4), 932-934 (1992)

17. A. Pal, K. Indireshkumar, W. Schwizer, B. Abrahamsson, M. Fried, J.G. Brasseur, Gastric flow and mixing studied using computer simulation. Proc. R. Soc. Lond. B Biol. Sci. 271, 25872594 (2004)

18. J.D. Selman, P. Rice, R.K. Abdul-Rezzak, A study of the apparent diffusion coefficients for solute losses from carrot tissue during blanching in water. International Journal of Food Science \& Technology 18(4), 401-538 (1983)

19. D.W. Stanley, M.C. Bourne, A.P. Stone, W.V. Wismer, Low temperature blanching effects on chemistry, firmness and structure of canned green beans and carrots. Journal of Food Science 60, 327 $333(1995)$

20. W.M. Sun, L.A. Houghton, N.W. Read, D.G. Grundy, A.G. Johnson, Effect of meal temperature on gastric emptying of liquids in man. Gut 29, 302-5 (1988) 